\title{
Ocular side effects of biological agents in oncology: what should the clinician be aware of?
}

This article was published in the following Dove Press journal:

OncoTargets and Therapy

24 December 2013

Number of times this article has been viewed

\section{Tobias Hager \\ B Seitz}

Department of Ophthalmology, Universitätsklinikum des Saarlandes, Homburg, Germany
Correspondence: Tobias Hager Department of Ophthalmology, Universitätklinikum des Saarlandes, Kirrberger Straße 100, 66424 Homburg, Germany $\mathrm{Tel}+490684 \mid \quad 1622334$

Email tobias.hager@uniklinikum-saarland. de
Abstract: During the last 20 years, biologicals have become increasingly relevant in oncologic therapy. Depending on the medication used, there are different profiles of ocular side effects. Although these can be present in up to $70 \%$ of patients, they are generally underreported in the literature. Therefore, the pathophysiological details of their development are often poorly understood. Herein we attempt to identify groups of biologicals to which a specific side effect profile can be assigned. We also tried to capture all relevant side effects and therefore conducted several database investigation including Medline, Cochrane library, and the drugs section of the US Food and Drug Administration (FDA), using the following search strings: "name of biological agent (both generic and commercial names)" AND “eye" OR "ocular". If we found a side effect that has been associated with a drug, we researched Medline using the following search string: "name of biological agent" (both generic and commercial names) AND "term for the specific side effect". Due to the wealth of material we report only the drugs that are approved by the FDA.

Keywords: ocular side effect, biological, targeted therapy, interferon, EGFR

\section{Introduction}

Over the past 20 years biological agents have been developed for the treatment of cancer. These are drugs that specifically affect growth and survival of cancer cells while leaving other tissues of the body largely unaffected. ${ }^{1,2}$ The terms targeted therapy, biologic response modifiers, or immunotherapy are also used to describe biological agents, all with overlapping meanings. ${ }^{1-3}$ There are various hypotheses regarding their interaction with cancer cells: they act on intracellular signaling of cancer cells via direct binding to transmembrane receptors or they inhibit intracellular tumor-specific proteins and they influence the growth of the tumor's own vessels or they trigger the immune system so that it is more susceptible to antigens of the tumor cells. ${ }^{1}$ It is expected that this approach has fewer side effects than more traditional cytotoxic drugs that act nonspecifically on all dividing cells of the body.

The eye, an organ that combines in complex ways the neural network system with blood vessels, muscles, and skin can be affected by side effects of these targeted agents. Ocular tissues often have different receptor-specific patterns ${ }^{4}$ that do not occur in this form elsewhere in the body. In addition, the eye is highly vascularized, but there are areas such as the fovea (the point of sharpest vision) or the cornea (most important for the total refractive power of the optical system) which are virtually only fed by diffusion. ${ }^{5}$ It should not be forgotten that the eye is a downstream portion of the brain and cerebral side effects of drugs may affect the visual pathways and the visual cortex. 
The National Cancer Institute developed a system to enable multidisciplinary reports of adverse drug reactions and to identify and classify these according to severity. ${ }^{6}$ In a review of publications on ocular side effects by the US Food and Drug Administration (FDA), which uses this system, there are reports of ocular side effects or visual disturbances of comparatively low significance at a rate of up to $60 \%,{ }^{7}$ while serious complications are only infrequently reported or not at all. This process runs the risk that no discipline feels responsible for their recognition. However, it is currently the oncologist as treating physician that is often the first to be confronted with ocular discomfort of the patient because they relate new ocular symptoms to the oncological therapy. In addition, there are few reports of side effects of targeted therapy on the eye. Studies on large numbers of patients are rare. If they exist, they have often been done as pivotal studies that provide a rather cursory glance at comparatively illdefined terms or symptoms, so that the non-ophthalmologist has difficulties weighing these symptoms according to their relevance. Very rarely, there are also studies on ophthalmic ocular side effects of biologic agents. If they exist, there is often only a small number of patients included; individual case reports clearly dominate. However, the more targeted therapy is used, the more specific side effects will be reported. So far, only three publications have collectively dealt with ocular side effects of biological agents. ${ }^{1,2,8}$

In this review, we summarize the ocular side effects of biological agents in oncology. We conducted several database investigations including Medline, Cochrane library, and the drugs section of the FDA, using the following search strings: "name of biological agent (both generic and commercial names)" AND “eye" OR “ocular" OR "ophthalmic". If we found a side effect that has been associated with the drug, we researched Medline using the following search string: "name of biological agent" (both generic and commercial names) AND "term for the specific side effect". We attempted to identify groups of biologicals to whom a specific side effect profile could be assigned (Table 1). We tried to elucidate these mechanisms and discuss recommendations for diagnosis and treatment. Due to the wealth of material available, we report only the drugs approved by the FDA and not those still in phase I or II clinical trials.

\section{Inhibitors of epidermal growth factor receptor}

Epidermal growth factor receptor (EGFR) inhibitors are used for the treatment of many solid tumors, including non-small cell bronchial carcinoma, pancreatic carcinoma, colorectal
Table I Biologicals with potential ocular side effects

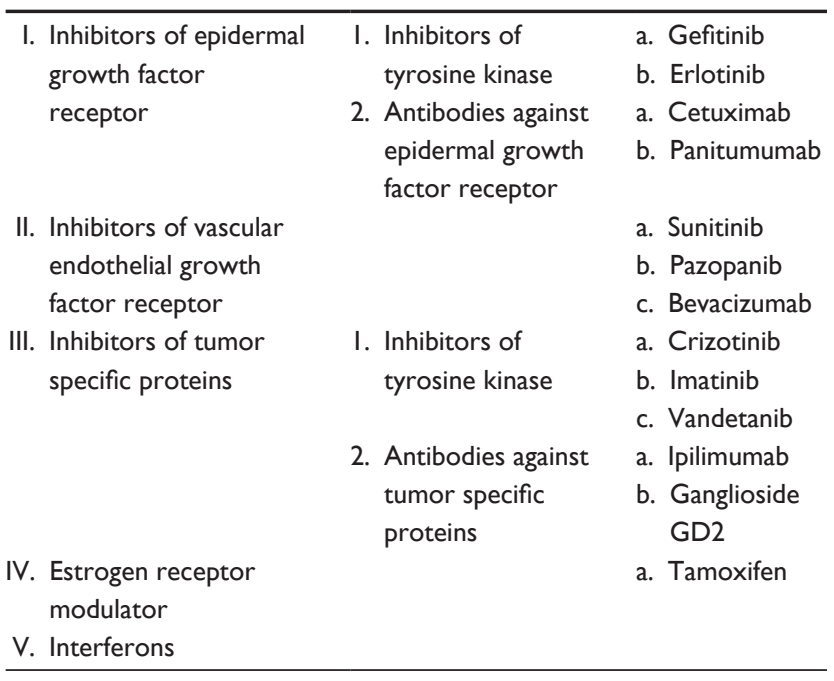

carcinoma, and basal cell carcinoma. ${ }^{9-12}$ EGFR is one of the key receptors in wound healing of the cornea. EGFR is expressed mainly in the corneal epithelial and endothelial cells and less commonly in the corneal stroma. ${ }^{4}$ After setting a corneal epithelial wound, EGFR is increasingly expressed and epithelial cells migrate into the wound area. Next, there is a shift: the immigrating epithelial cells express EGFR and increase their proliferation rate by binding EGF. ${ }^{13}$ EGF is mainly expressed in the tear fluid. ${ }^{14}$ If the tyrosine kinase of EGFR is inhibited, corneal wound healing is delayed. ${ }^{15}$ EGF stimulates proliferation of the epithelial cells of the meibomian glands in the eyelids. ${ }^{16}$ If the effect of EGF is inhibited, meibomian glands become inflamed. ${ }^{17}$

EGFR is also expressed in the hair follicle. Inhibition in these cells leads to terminal dedifferentiation and significant growth of the eyelashes, the so-called trichomegaly. ${ }^{18}$ It has been postulated that trichomegaly under EGFR inhibitor treatment, which is analogous to acneiform rash, is a sign of a positive response to therapy. But until now, available data are not sufficient to form definitive conclusions. ${ }^{18}$ Trichomegaly occurs regardless of whether the therapy is gefitinib, ${ }^{19}$ erlotinib, cetuximab, ${ }^{20}$ or panitumumab. ${ }^{11}$ Gefitinib and erlotinib inhibit the tyrosine kinase of EGFR, ${ }^{21}$ whereas cetuximab and panitumumab are monoclonal antibodies that bind to EGFR directly. ${ }^{20,21}$ Since both the monoclonal antibody and the specific tyrosine kinase inhibitors act on the same final pathway, we observe similar ocular side effect profiles, which occur in oncological studies in up to $30 \%$ of patients. ${ }^{21}$ Borkar et al report in the most extensive study with 69 patients ocular side effects in about $60 \%$ of patients..$^{20}$ There is a dose-dependency of ocular side effects: the higher the dose, the bigger the risk for complications. ${ }^{11}$ Comparatively harmless findings, such 
as blepharitis and conjunctivitis, occur in $3.5 \%$ to $14.5 \%$ of patients treated with gefitinib and these are usually transient (Figure 1). ${ }^{19}$ The patient complains of red eyes and eyelids, and foreign body sensation. In addition, reduced visual acuity may be reported. This seems to be characteristic after repeated blinking which distributes tears on the surface of the eye, and visual acuity usually returns afterwards. In extreme cases, cicatricial ectropion may develop based on cetuximab induced blepharitis. ${ }^{22}$ Ectropion has also been described during treatment with erlotinib. ${ }^{23}$

Approximately $1 \%$ of patients treated with gefitinib $250 \mathrm{mg}$ develop a corneal erosion. ${ }^{11,19}$ There are cofactors that may favor the development of a corneal erosion, especially when it comes to dysfunction of the lids in cachectic patients. An additional "traditional" chemotherapy contributes to the development of dry eye syndrome as a result of aberrant eyelashes rubbing on the cornea (trichiasis). There is one report of the development of refractory corneal erosion during cetuximab therapy, which healed following local application of EGF; cetuximab therapy did not need to be interrupted. ${ }^{24}$ The worst case scenario is the progression of corneal erosion to corneal perforation under EGFR inhibitors, which has been described for gefitinib, panitumumab, and erlotinib. ${ }^{25,23}$

Thus, artificial tear use for the duration of the therapy at least four times per day should be recommended to patients receiving EGFR inhibitors. If under this prophylactic therapy complaints persist, an ophthalmic evaluation should be indicated. In cases of trichomegaly contributing to corneal erosion, a simple epilation of the eyelashes can be performed. For pure trichomegaly no treatment is necessary.

\section{Inhibitors of vascular endothelial growth factor receptor}

Vascular endothelial growth factor (VEGF) inhibitors have been used in ophthalmology for more than 10 years. Intraocular application of VEGF receptor tyrosine kinase inhibitors results in damage to the photoreceptor layer. ${ }^{26}$

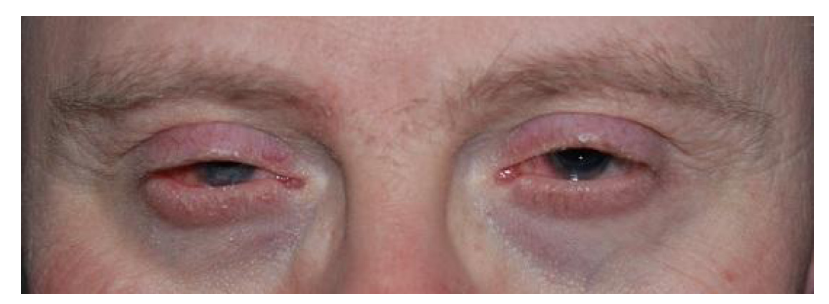

Figure I Swollen eyelids on both sides. The lids have a reddish tint despite the rather pale complexion of the patient. At the same time, there is a conjunctival hyperemia, temporally in the right eye and nasally in the left eye. However, conjunctival hyperemia is not a drug effect, but is due to the development of a pseudopterygium (right eye at 8:00 on the cornea).
Sunitinib and pazopanib belong to the tyrosine kinase inhibitor class. ${ }^{27,28}$ Sunitinib inhibits both VEGF-2 and platelet derived growth factor (PDGF)-beta receptor and is used for treatment of renal cell carcinoma and gastrointestinal stromal tumors (GIST) ${ }^{27}$ Sunitinib can lead to reversible posterior leukencephalopathy syndrome (RPLS). ${ }^{27}$ This disease is defined by encephalopathy due to a disturbance of cerebral vascular autoregulation, which leads to hyperperfusion with dilation of cerebral arterioles. The endothelium cannot withstand this pressure, so a breakdown of the blood-brain barrier results. ${ }^{29}$ This goes along with visual disturbances ${ }^{27}$ and other neurological symptoms (vigilance, headache, and generalized seizure). ${ }^{28,30}$ The symptoms occur not earlier than 1 -week after initiation of treatment, but can also start after 8 months. ${ }^{28}$

Diagnosis is made via magnetic resonance imaging (MRI). ${ }^{26}$ In the T2-weighted image, there is a diffuse parieto-occipital hyperintensity in the gray matter. ${ }^{26} \mathrm{It}$ is unclear whether the potentially endothelial damaging effect is sufficient to be causative for the disease or whether additional arterial hypertony as a pre-existing condition must be present. ${ }^{26}$ It is known that arterial hypertony itself is a risk factor for the development of RPLS. ${ }^{28}$ The disease is only reversible if adequate management is applied, in particular a reduction in blood pressure $;^{28}$ otherwise, residuals may remain, especially loss of visual acuity due to centrocaecal scotoma. Regression takes place within the first 3 weeks after onset of RPLS. ${ }^{27}$ The vision problems are a possible sign of RPLS, but not mandatory. ${ }^{31}$ They develop because of edema in the area of the visual cortex, which leads - depending on its location - to a central visual field defect.

Bevacizumab is a monoclonal antibody that is used for the treatment of colorectal carcinoma. ${ }^{30} \mathrm{~A}$ reversible posterior leukencephalic syndrome under bevacizumab treatment has been reported..$^{32}$ It is believed that a bevacizumab induced vasospasm triggers the syndrome. ${ }^{32}$ This can cause cortical blindness, which is not fully reversible. ${ }^{30}$

\section{Crizotinib}

Crizotinib is an inhibitor of the anaplastic lymphoma kinase, a tyrosine kinase. It is used for the treatment of non-small cell lung cancer. Ocular problems occur in up to $42 \%$ of patients ${ }^{33}$ within the first 2 weeks after initiation of therapy. ${ }^{7}$ Visual effects are described as light trails, flashes, or brief image persistence (post-flashbulb effect). Investigators reported that these visual effects are most pronounced upon changing from low light to bright light conditions. ${ }^{7}$ The FDA therefore classified the severity of this condition as minor. 


\section{Imatinib}

Imatinib is a selective inhibitor of several tyrosine kinases (bcr-abl, c-kit proto-oncogene, and PDGF receptor kinase) that is used for the treatment of chronic myeloid leukemia (CML) and GIST. ${ }^{2}$ Seventy percent of treated patients develop periorbital edema (Figure 2). ${ }^{34}$ The edema usually occurs between 5 weeks and 8 weeks after starting the treatment, but can occur as early as after 24 hours or as late as after 1-year, depending on the dose. ${ }^{34}$ The periocular dermal dendrocytes express c-kit and PDGF receptor (PDGFR). ${ }^{34}$ The current hypothesis is that through the inhibition of PDGFR interstitial fluid accumulates. The development of conjunctival hemorrhage, which regresses completely, has also been reported. However, this can also be due to the underlying CML disease,${ }^{34}$ which is often associated with thrombocytopenia. In five patients with refractory GIST who were treated with a combination of imatinib and perifosine, a drug that inhibits the signaling pathway through phosphoinositide 3-kinase, ulcerative keratitis with perilimbal infiltrates developed similar to in rheumatoid arthritis, which responded well to topical steroid administration. ${ }^{35}$ It is unclear whether this side effect is attributable only to the combination of imatinib and perifosine, or whether it is a single effect of perifosine. There are two reports in the literature about the development of optic disc edema under therapy with imatinib. One patient had unilateral disc edema, the other bilateral. ${ }^{36,37}$ It might represent a mild form of papillitis. People with this condition complain of a loss of visual acuity and photopsia. In addition, possible optic neuritis during treatment with imatinib has been described by two authors independent from each other. ${ }^{34,38}$ Five to seven days after discontinuation of therapy with imatinib, the visual problems resolved rapidly and the morphological changes regressed..$^{36-38}$ The underlying pathophysiology remains unknown.

The periorbital edema is often mild, and does not require therapy. In severe cases, blepharoplasty can be performed and treatment with imatinib can be continued. ${ }^{39}$ An alternative option for patients rejecting an operation would be a trial of conservative therapy with diuretics.

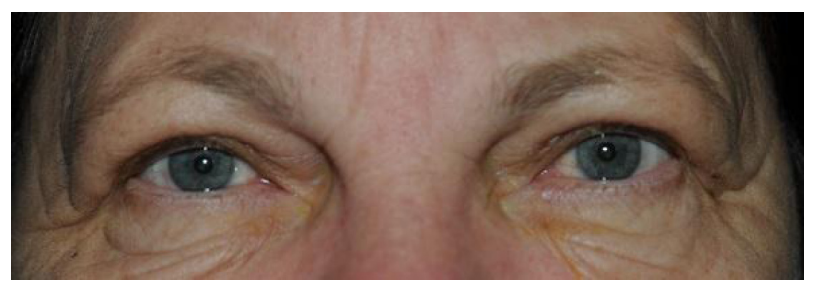

Figure 2 Slight periorbital edema, not inducing ptosis or dermatochalasis, no treatment necessary.

\section{Vandetanib}

Vandetanib inhibits the tyrosine kinase of both EGFR and VEGF receptor (VEGFR) 2. It is used for the treatment of non-small cell lung cancer. There are several reports of the development of a cornea verticillata during vandetanib therapy. ${ }^{40,41} \mathrm{~A}$ cornea verticillata appears as vortex-like brownish lines within the corneal epithelium. It is assumed that these lines develop because of the interference of vandetanib with EGFR. ${ }^{41}$ The reason for the vortex shape is attributable to the migration behavior of the corneal epithelial cells. ${ }^{42}$ The deposits lead to only minor visual disturbances including blurred vision, if any ${ }^{40}$ Interruption of therapy is therefore not necessary. It is well known from other drugs - in particular amiodarone - that the amount of deposits corresponds to the duration of treatment. However, there is a complete regression of the lesions after cessation of therapy, though this may take months. ${ }^{42}$

\section{Ipilimumab}

Ipilimumab is a human monoclonal antibody that is used for the treatment of metastatic malignant melanoma. The antigen-presenting cell (APC) presents tumor cell antigens to T-cells via the major histocompatibility complex (MHC). The T-cell binds to the APC and a T-cell response is triggered. In order to terminate the T-cell response, T-cells also bind to the cytotoxic t-lymphocyte antigen (CTLA) 4-receptor on the APC. Ipilimumab binds to CTLA4, thus inhibiting the binding and enhancing the T-cell response. ${ }^{43}$

In $5 \%-17 \%$ of patients treated with ipilimumab, changes in the pituitary gland occur. ${ }^{43,44}$ Symptoms usually appear 6 to 12 weeks after the start of therapy ${ }^{45}$ Symptoms similar to Graves disease are reported: dry eye, proptosis, and swelling of the extraocular muscles. ${ }^{45,46}$ These are probably associated with polymorphisms of the CTLA4 receptor. ${ }^{46}$ These symptoms do not occur in all patients with changes in the pituitary gland. Systemic steroids for the treatment of this ocular side effect have no negative impact on the overall response of the body to ipilimumab therapy ${ }^{47} \mathrm{After}$ tapering off steroids, a relapse can occur. ${ }^{45}$ Therefore, steroids should be slowly phased out over weeks. Leclouflet et al reported a case of orbital myositis with ipilimumab treatment. ${ }^{48}$ The patient suffered from painful diplopia which resolved under systemic steroid therapy. Although this is the only report of such a condition in the eye, autoimmune myositis during ipilimumab therapy can also be demonstrated histologically in the deltoid muscle. ${ }^{49}$

There have been rare reports on the development of bilateral iridocyclitis under ipilimumab therapy. 
Patients with iridocyclitis complain of vision loss and floaters. All patients who developed iridocyclitis with ipilimumab were previously subcutaneously treated with antibodies against glykoproteine 100 (gp100). ${ }^{50}$ Melanocyte specific gp100 is a protein expressed by melanoma cells. Vaccination with anti-gp100 is intended to suppress the development of melanoma. ${ }^{51}$ Thus, a cross-reaction of the antibody with the iris pigment epithelium or a cross-reaction because of a reinforced T-cell response are also potential causes for the development of this type of iridocyclitis.

Modjtahedi et al report the development of a multifocal bilateral choroidal neovascularization during therapy with ipilimumab. ${ }^{52}$ Because this is the only report of this side effect, it is hard to distinguish whether it is a real side effect or only a coincidence. A bilateral multifocal choroidal neovascularization is also typical for polypoidal choroidal vasculopathy ${ }^{53}$ and can therefore occur independent of ipilimumab treatment.

\section{Ganglioside GD2 antibodies}

Ganglioside GD2 is a glycosphingolipid, which is highly expressed on neuroblastoma cells. ${ }^{54}$ Therefore, it is an interesting target for the treatment with monoclonal antibodies against GD2. Currently, the chimeric human-mouse antibody ch14.18 is used for neuroblastoma treatment. ${ }^{55}$ The largest group studied with respect to side effects included 85 children; ten children showed ocular symptoms, manifesting as parasympathic lesions with mydriasis and deficiency of accommodation. ${ }^{56}$ The symptoms started only after the end of the antibody therapy and persisted up to one year, but fully regressed or at least improved. ${ }^{56}$ To date, there are only attempts to explain this phenomenon without solid evidence.
GD2 is also expressed in the ciliary body and the iris, so a cross-reaction with the antibody is possible. ${ }^{56}$ The children were sensitive to glare, so ophthalmologic co-supervision is useful (a therapeutic attempt with pilocarpine $0.1 \%$ and bifocal sunglasses is useful).

\section{Tamoxifen}

Tamoxifen is a selective estrogen receptor modulator that is used as an adjuvant therapy for breast cancer. Between $0.6 \%$ and $12 \%$ of patients experience damage to ocular structures. ${ }^{57,58}$ Classically, side effects of the eye include crystalline retinopathies, which do not usually lead to visual disturbances. The crystalline deposits focus in the macular area (Figure 3), but can also occur in the peripheral retina. ${ }^{59}$ With the advancement of optical coherence tomography (OCT), there are also reports in which crystalline retinal deposits occur along with structural changes in the macula. The most common is a cystoid structure without evidence of macular edema. This can also occur without crystalline changes and leads to a pronounced loss of vision. ${ }^{60}$ The mechanism of this condition is unknown. It is controversial whether selective hormone medication leads to an increased risk of vitreoretinal traction; conclusive proof has not yet been provided. ${ }^{61}$ Macular edema with severe visual loss is also one of the classic appearances of tamoxifen associated retinopathy. ${ }^{62}$ It has been described mainly in patients with a high total cumulative dose. An Australian research group reported the occurrence of a macular hole with a frequency of $4.12 \%$ in patients treated with tamoxifen compared to $0.8 \%$ in the normal population. It should be noted that breast cancer patients may also have other risk factors for development of a macular hole. ${ }^{63}$ Due to the rarity of the injury picture,

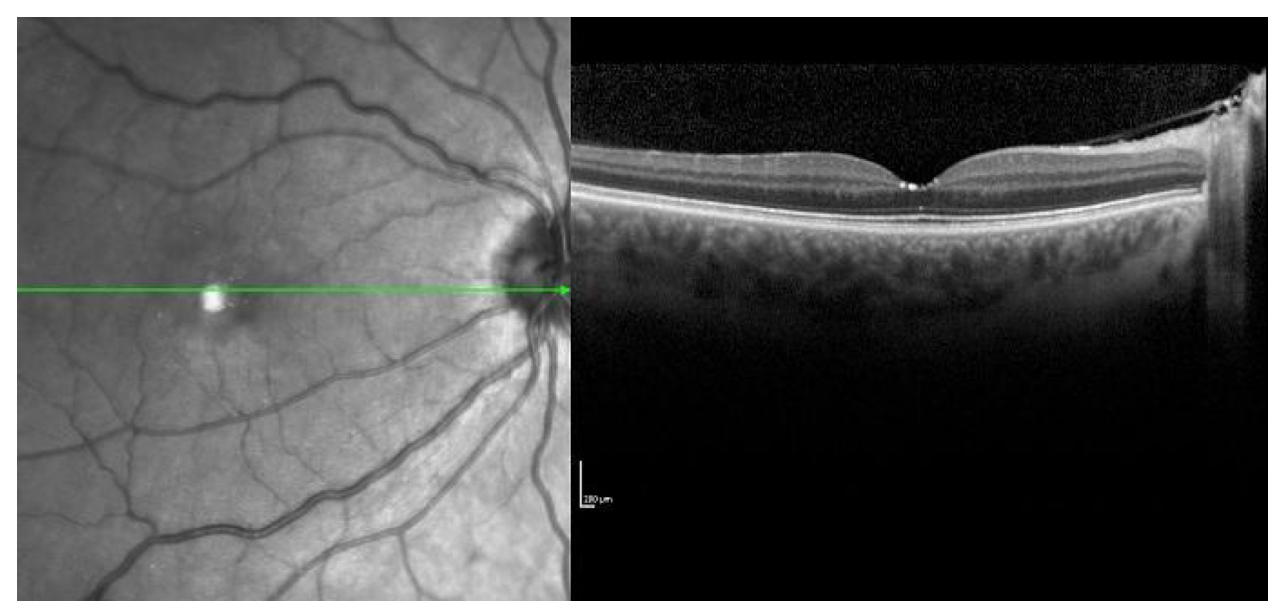

Figure 3 Horizontal scan with optical coherence tomography through the fovea. The foveal depression shows several hyperreflective structures as a sign of crystalline retinopathy. 
it was not possible to determine whether cystoid foveolar structure, macular edema, and macular hole follow each other in a pathophysiological chain, or whether they are independent reactions based on the same noxa. So far, it has been proven that tamoxifen crosses the blood-aqueous barrier and can be detected both in the aqueous humor and in the vitreous. ${ }^{64}$ In vitro, tamoxifen may have toxic effects on cells of the retinal pigment epithelium ${ }^{65}$ and inhibit its phagocytic activity. ${ }^{66}$ In cell culture, retinal pigment epithelial cells and photoreceptor cells undergo cell death within 18 hours after exposure to tamoxifen. ${ }^{67}$

In addition, Eisner et al demonstrated reduced size of the optic nerve head compared to normal patients, which they explained as subclinical swelling of astrocytes. ${ }^{68}$ There are case reports on the occurrence of optic neuritis on tamoxifen therapy with centrocoecal scotoma and visual loss which resolved after interruption of treatment. ${ }^{69}$ Therefore, if visual disturbances occur under tamoxifen therapy, an immediate ophthalmologic consultation is mandatory.

\section{Interferons}

After an observation period of one year, $42 \%$ of patients developed interferon-associated retinopathy. ${ }^{70}$ After 3 months of therapy, $16 \%$ show interferon-associated alterations in the retina. ${ }^{71}$ The retinopathy seems to occur mainly temporarily, ${ }^{71}$ and it is an ischemic change of the ocular fundus (Figure 4). Typical characteristics are retinal hemorrhages and cotton-wool spots as a sign of swelling of nerve fibers. These changes are similar to the clinical findings in diabetic retinopathy and arterial hypertension. However, patients with diabetes mellitus and/or arterial hypertension seem to have no increased risk for the development of an interferon-associated retinopathy. ${ }^{72}$ Some patients that have morphological changes do not even present with ocular symptoms. ${ }^{71}$ There are two theories for this pathology: 1) interferon stimulates the formation of immune complexes, and these are deposited in the blood vessels and lead to vascular occlusion and ischemia; ${ }^{73}$ or 2) interferons lead to vasospasms that cause occlusion of the retinal vessels. ${ }^{74}$

Meanwhile, there are several reports of combined vascular occlusion (artery and vein) during interferon therapy. ${ }^{75,76}$ Interestingly, no fundus abnormalities were seen in the fellow eye.

During interferon therapy, anterior ischemic optic neuropathy (AION) has been reported in 36 patients. ${ }^{77} \mathrm{AION}$ is a closure of the small capillaries that supply the optic nerve head, which is associated with partial amputation of the visual field and often a dramatic loss of visual acuity. In $60 \%$ of patients, AION appeared on both sides. ${ }^{77}$ In approximately $50 \%$ of patients, the visual impairment remained even after discontinuation of interferon therapy. ${ }^{77}$ Since the aim of the abovementioned study was to identify the association between AION and interferon therapy, it contained no information about the partner eye, but in the case reports of AION during interferon therapy, no changes in the sense of interferon retinopathy were described, regardless of whether AION was unilateral or bilateral. ${ }^{78,79}$

Very rarely, myasthenia gravis may develop during interferon therapy. ${ }^{80}$ These patients complain about double vision. The pathophysiological causes are not known but are probably related to the complex immunological effects of interferons. In connection with these immunological effects, a case report exists of a sixth nerve palsy in a patient with renal cell carcinoma that regressed without discontinuation of interferon within 5 months. ${ }^{81}$ The correlations are, however, so far only assumed.

Regular ophthalmologic screening examination for patients on interferon therapy appears not indicated upon this data. Interferon retinopathy may be associated with nonspecific ocular symptoms, but does not require direct withdrawal of the interferon. If there is progression of the clinical findings or symptoms, interferon should be discontinued. Dramatic events such as combined vascular occlusion or AION always require discontinuation of interferon therapy

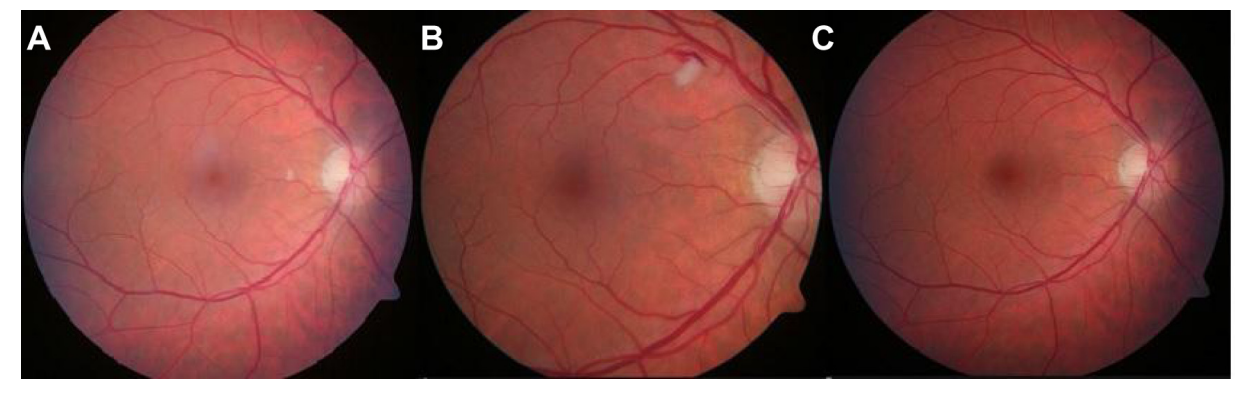

Figure 4 Patient during interferon therapy. (A) At first presentation, two cotton-wool spots; (B) after 6 weeks, line-shaped retinal hemorrhage at a cotton-wool spot and visual disturbances (progression of interferon retinopathy); (C) 4 weeks after discontinuation of therapy, the findings have completely regressed. 
and a lifelong antiplatelet therapy with aspirin. Myasthenia gravis and sixth nerve palsy are possible side effects of interferon therapy, but may also be considered a paraneoplastic syndrome due to the underlying malignant disease. ${ }^{82}$

\section{Discussion}

Biological agents represent a promising treatment option for cancer patients. They are, however, relatively new with respect to their clinical application and their effects on other tissues are not fully understood thus far. The side effect profile of some biologicals is well studied. The longer a drug is in clinical use, the better statements can be made about the side effect profile. However, there are still observations that lead to the presumption of new adverse drug reactions even with clinical drugs such as tamoxifen that have already been in clinical use for an extended period of time. Conversely, there are only individual case reports in the literature on recently introduced clinical agents about possible side effects. These are necessary to be ever vigilant of possible side effects, but can never lead to a conclusive etiological connection.

The danger for all targeted agents is that their side effects may be overlooked. This is complicated by the fact that oncologic therapy is often performed as a protocol of several different drugs. Sometimes, as seen for the use of ipilimumab, even the ophthalmologist is not able to distinguish whether the ocular complaints of a patient are due to a side effect of a specific drug, due to the concomitant use of other medications or if this ocular side effect occurs only in combination with drugs acting on various signal pathways.

The question that arises in particular for the oncologist is whether a prophylactic ophthalmic screening protocol is useful. The question can be clearly answered with "no" on the basis of the available data. It might only be useful to conduct a basic screening at beginning of the therapy and re-presentation, when ocular symptoms are observed by the patient. If the oncologist makes this suggestion, the treatment regimen should be given to the patient so that the ophthalmologist can give expert advice on the possible ocular symptoms. Overall, the detection of ocular complications in time requires a close contact between the oncologist and the ophthalmologist. Specifically, prophylactic administration of artificial tears when using EGFR inhibitors is strongly recommended.

In severe cases of ocular side effects, a reduction of the dose of the drug used should be performed initially, combined with close ophthalmological examinations. If the symptoms progress or no improvement in the results is seen, cessation of the biological therapy is indicated. This usually leads to an improvement of side effects.

\section{Conclusion}

The ocular side effects of biologicals are clinically relevant and can be present in up to $70 \%$ of patients depending on the medication used. Because no screening protocol is recommended, ophthalmologists and oncologists should be vigilant; however, a dose reduction or cessation of therapy is only rarely necessary.

\section{Disclosure}

The authors report no conflicts of interest in this work.

\section{References}

1. Ho WL, Wong H, Yau T. The ophthalmological complications of targeted agents in cancer therapy: what do we need to know as ophthalmologists? Acta Ophthalmol. 2012.

2. Renouf DJ, Velazquez-Martin JP, Simpson R, Siu LL, Bedard PL. Ocular toxicity of targeted therapies. J Clin Oncol. 2012;30(26): 3277-3286.

3. Kirkwood JM, Butterfield LH, Tarhini AA, Zarour H, Kalinski P, Ferrone S. Immunotherapy of cancer in 2012. CA Cancer J Clin. 2012;62(5):309-335.

4. Klenkler B, Sheardown H. Growth factors in the anterior segment: role in tissue maintenance, wound healing and ocular pathology. Exp Eye Res. 2004;79(5):677-688.

5. Chalam KV, editor. Basic and Clinical Science Course: Fundamentals and Principles of Ophthalmology. 1st ed. San Francisco: American Academy of Ophthalmology; 2011.

6. National Cancer Institute. Common Terminology Criteria for Adverse Events (CTCAE) Version 4.0. National Cancer Institute; 2010. Available from: http://evs.nci.nih.gov/ftp1/CTCAE/CTCAE_4.03_2010-0614_QuickReference_5x7.pdf. Accessed October 11, 2013.

7. Pfizer Labs. Food and Drug Administration: Highlights of Prescribing Information XALKORI. New York: Pfizer Labs; 2011. Available from: http:/www.accessdata.fda.gov/drugsatfda_docs/ label/2011/202570s0001bl.pdf. Accessed October 11, 2013.

8. Agustoni F, Platania M, Vitali M, et al. Emerging toxicities in the treatment of non-small cell lung cancer: Ocular disorders. Cancer Treat Rev. 2013.

9. Camidge DR, Bang YJ, Kwak EL, et al. Activity and safety of crizotinib in patients with ALK-positive non-small-cell lung cancer: updated results from a phase 1 study. Lancet Oncol. 2012;13(10): 1011-1019.

10. Fraunfelder FW, Solomon J, Druker BJ, Esmaeli B, Kuyl J. Ocular sideeffects associated with imatinib mesylate (Gleevec). J Ocul Pharmacol Ther. 2003;19(4):371-375.

11. Fabbrocini G, Panariello L, Cacciapuoti S, Bianca D, Ayala F. Trichomegaly of the eyelashes during therapy with epidermal growth factor receptor inhibitors: report of 3 cases. Dermatitis. 2012;23(5): 237-238.

12. Saint-Jean A, Sainz de la Maza M, Morral M, et al. Ocular adverse events of systemic inhibitors of the epidermal growth factor receptor: report of 5 cases. Ophthalmology. 2012;119(9):1798-1802.

13. Xu KP, Ding Y, Ling J, Dong Z, Yu FS. Wound-induced HB-EGF ectodomain shedding and EGFR activation in corneal epithelial cells. Invest Ophthalmol Vis Sci. 2004;45(3):813-820.

14. Enríquez-de-Salamanca A, Castellanos E, Stern ME, et al. Tear cytokine and chemokine analysis and clinical correlations in evaporative-type dry eye disease. Mol Vis. 2010;16:862-873. 
15. Nakamura Y, Sotozono C, Kinoshita S. The epidermal growth factor receptor (EGFR): role in corneal wound healing and homeostasis. Exp Eye Res. 2001;72(5):511-517.

16. Liu S, Kam WR, Ding J, Hatton MP, Sullivan DA. Effect of growth factors on the proliferation and gene expression of human meibomian gland epithelial cells. Invest Ophthalmol Vis Sci. 2013;54(4): 2541-2550.

17. Fraunfelder FT, Fraunfelder FW. Trichomegaly and other external eye side effects associated with epidermal growth factor. Cutan Ocul Toxicol. 2012;31(3):195-197.

18. Alexandrescu DT, Kauffman CL, Dasanu CA. Persistent hair growth during treatment with the EGFR inhibitor erlotinib. Dermatol Online J. 2009;15(3):4.

19. Tullo AB, Esmaeli B, Murray PI, Bristow E, Forsythe BJ, Faulkner K. Ocular findings in patients with solid tumours treated with the epidermal growth factor receptor tyrosine kinase inhibitor gefitinib ('Iressa', ZD1839) in Phase I and II clinical trials. Eye (Lond). 2005;19(7): 729-738.

20. Borkar DS, Lacouture ME, Basti S. Spectrum of ocular toxicities from epidermal growth factor receptor inhibitors and their intermediateterm follow-up: a five-year review. Support Care Cancer. 2013;21(4): 1167-1174.

21. Soulieres D, Senzer NN, Vokes EE, Hidalgo M, Agarwala SS, Siu LL. Multicenter phase II study of erlotinib, an oral epidermal growth factor receptor tyrosine kinase inhibitor, in patients with recurrent or metastatic squamous cell cancer of the head and neck. J Clin Oncol. 2004;22(1): 77-85.

22. Garibaldi DC, Adler RA. Cicatricial ectropion associated with treatment of metastatic colorectal cancer with cetuximab. Ophthal Plast Reconstr Surg. 2007;23(1):62-63.

23. Saint-Jean A, Sainz de la Maza M, Morral M, et al. Ocular adverse events of systemic inhibitors of the epidermal growth factor receptor: report of 5 cases. Ophthalmology. 2012;119(9):1798-1802.

24. Foerster CG, Cursiefen C, Kruse FE. Persisting corneal erosion under cetuximab (Erbitux) treatment (epidermal growth factor receptor antibody). Cornea. 2008;27(5):612-614.

25. Ibrahim E, Dean WH, Price N, et al. Perforating corneal ulceration in a patient with lung metastatic adenocarcinoma treated with gefitinib: a case report. Case Rep Ophthalmol Med. 2012;2012:379132.

26. Dib E, Maia M, Lima Ade S, et al. In vivo, in vitro toxicity and in vitro angiogenic inhibition of sunitinib malate. Curr Eye Res. 2012;37(7): 567-574.

27. Kapiteijn E, Brand A, Kroep J, Gelderblom H. Sunitinib induced hypertension, thrombotic microangiopathy and reversible posterior leukencephalopathy syndrome. Ann Oncol. 2007;18(10): 1745-1747.

28. Chelis L, Souftas V, Amarantidis K, et al. Reversible posterior leukoencephalopathy syndrome induced by pazopanib. BMC Cancer. 2012;12:489.

29. Tam CS, Galanos J, Seymour JF, Pitman AG, Stark RJ, Prince HM. Reversible posterior leukoencephalopathy syndrome complicating cytotoxic chemotherapy for hematologic malignancies. Am J Hematol. 2004;77(1):72-76.

30. Allen JA, Adlakha A, Bergethon PR. Reversible posterior leukoencephalopathy syndrome after bevacizumab/FOLFIRI regimen for metastatic colon cancer. Arch Neurol. 2006;63(10):1475-1478.

31. Hadj JO, Braven RD, Tillier C, Schrijver HM, Verheul HM, VAN DER Vliet HJ. Reversible posterior leukoencephalopathy syndrome during sunitinib therapy for metastatic renal cell carcinoma. Oncol Lett. 2012;3(6):1293-1296.

32. Ozcan C, Wong SJ, Hari P. Reversible posterior leukoencephalopathy syndrome and bevacizumab. N Engl J Med. 2006;354(9):980-982; discussion 980-982.

33. Shaw AT, Yeap BY, Solomon BJ, et al. Effect of crizotinib on overall survival in patients with advanced non-small-cell lung cancer harbouring ALK gene rearrangement: a retrospective analysis. Lancet Oncol. 2011;12(11):1004-1012.
34. Breccia M, Gentilini F, Cannella L, et al. Ocular side effects in chronic myeloid leukemia patients treated with imatinib. Leuk Res. 2008;32(7): 1022-1025.

35. Shome D, Trent J, Espandar L, et al. Ulcerative keratitis in gastrointestinal stromal tumor patients treated with perifosine. Ophthalmology. 2008;115(3):483-487.

36. DeLuca C, Shenouda-Awad N, Haskes C, Wrzesinski S. Imatinib mesylate (Gleevec) induced unilateral optic disc edema. Optom Vis Sci. 2012;89(10):e16-e22.

37. Kwon SI, Lee DH, Kim YJ. Optic disc edema as a possible complication of Imatinib mesylate (Gleevec). Jpn J Ophthalmol. 2008;52(4): 331-333.

38. Govind Babu K, Attili VS, Bapsy PP, Anupama G. Imatinib-induced optic neuritis in a patient of chronic myeloid leukemia. Int Ophthalmol. 2007;27(1):43-44.

39. McClelland CM, Harocopos GJ, Custer PL. Periorbital edema secondary to imatinib mesylate. Clin Ophthalmol. 2010;4:427-431.

40. Yeh S, Fine HA, Smith JA. Corneal verticillata after dual anti-epidermal growth factor receptor and anti-vascular endothelial growth factor receptor 2 therapy (vandetanib) for anaplastic astrocytoma. Cornea. 2009;28(6):699-702.

41. Ahn J, Wee WR, Lee JH, Hyon JY. Vortex keratopathy in a patient receiving vandetanib for non-small cell lung cancer. Korean $J$ Ophthalmol. 2011;25(5):355-357.

42. Schlote T, Freudenthaler SM, Stübiger N, Zierhut M. Medikamentöse Nebenwirkungen am Auge. 1. Auflage, Stuttgart: Thieme, 2001.

43. Dillard T, Yedinak CG, Alumkal J, Fleseriu M. Anti-CTLA-4 antibody therapy associated autoimmune hypophysitis: serious immune related adverse events across a spectrum of cancer subtypes. Pituitary. 2010; 13(1):29-38.

44. Blansfield JA, Beck KE, Tran K, et al. Cytotoxic T-lymphocyteassociated antigen-4 blockage can induce autoimmune hypophysitis in patients with metastatic melanoma and renal cancer. J Immunother. 2005;28(6):593-598.

45. Min L, Vaidya A, Becker C. Thyroid autoimmunity and ophthalmopathy related to melanoma biological therapy. Eur J Endocrinol. 2011;164(2): 303-307.

46. Borodic GE, Hinkle DM. Reply Re: "Drug-induced Graves disease from CTLA-4 receptor suppression". Ophthal Plast Reconstr Surg. 2003;29(3):241.

47. Downey SG, Klapper JA, Smith FO, et al. Prognostic factors related to clinical response in patients with metastatic melanoma treated by CTL-associated antigen-4 blockade. Clin Cancer Res. 2007;13(22 Pt 1): 6681-6688.

48. Lecouflet M, Verschoore M, Giard C, et al. [Orbital myositis associated with ipilimumab]. Ann Dermatol Venereol. 2013;140(6-7):448-451. French.

49. Hunter G, Voll C, Robinson CA. Autoimmune inflammatory myopathy after treatment with ipilimumab. Can J Neurol Sci. 2009;36(4): $518-520$.

50. Robinson MR, Chan CC, Yang JC, et al. Cytotoxic T lymphocyteassociated antigen 4 blockade in patients with metastatic melanoma: a new cause of uveitis. J Immunother. 2004;27(6):478-479.

51. Kalli F, Machiorlatti R, Battaglia F, et al. Comparative analysis of cancer vaccine settings for the selection of an effective protocol in mice. J Transl Med. 2013;11:120.

52. Modjtahedi BS, Maibach H, Park S. Multifocal bilateral choroidal neovascularization in a patient on ipilimumab for metastatic melanoma. Cutan Ocul Toxicol. 2013;32(4):341-343.

53. Ciardella AP, Donsoff IM, Huang SJ, Costa DL, Yannuzzi LA. Polypoidal choroidal vasculopathy. Surv Ophthalmol. 2004;49(1): 25-37.

54. Castel V, Segura V, Cañete A. Treatment of high-risk neuroblastoma with anti-GD2 antibodies. Clin Transl Oncol. 2010;12(12):788-793.

55. Simon T, Hero B, Faldum A, et al. Long term outcome of high-risk neuroblastoma patients after immunotherapy with antibody ch14.18 or oral metronomic chemotherapy. BMC Cancer. 2011;11:21. 
56. Kremens B, Hero B, Esser J, et al. Ocular symptoms in children treated with human-mouse chimeric anti-GD2 mAb ch14.18 for neuroblastoma. Cancer Immunol Immunother. 2002;51(2):107-110.

57. Gianni L, Panzini I, Li S, et al; International Breast Cancer Study Group (IBCSG). Ocular toxicity during adjuvant chemoendocrine therapy for early breast cancer: results from International Breast Cancer Study Group trials. Cancer. 2006;106(3):505-513.

58. Noureddin BN, Seoud M, Bashshur Z, Salem Z, Shamseddin A, Khalil A. Ocular toxicity in low-dose tamoxifen: a prospective study. Eye (Lond) 1999;13(Pt 6):729-733.

59. Ritter C, Renner AB, Wachtlin J, Bechrakis NE, Krause L. [Tamoxifen retinopathy: a case series of clinical and functional data]. Ophthalmologe. 2008;105(6):544-549. German.

60. Hager T, Hoffmann S, Seitz B. [Unusual symptoms for tamoxifenassociated maculopathy]. Ophthalmologe. 2010;107(8):750-752. German.

61. Eisner A, Thielman EJ, Falardeau J, Vetto JT. Vitreo-retinal traction and anastrozole use. Breast Cancer Res Treat. 2009;117(1):9-16.

62. Yanyali AC, Freund KB, Sorenson JA, Slakter JS, Wheatley HM. Tamoxifen retinopathy in a male patient. Am J Ophthalmol. 2001; 131(3):386-387.

63. Cronin BG, Lekich CK, Bourke RD. Tamoxifen therapy conveys increased risk of developing a macular hole. Int Ophthalmol. 2005; 26(3):101-105.

64. Flaxel CJ, Mulholland B, Haynes B, Gregor ZJ. Intraocular penetration of tamoxifen. Ophthalmology. 2000;107(11):2006-2009.

65. Mannerström M, Zorn-Kruppa M, Diehl H, et al. Evaluation of the cytotoxicity of selected systemic and intravitreally dosed drugs in the cultures of human retinal pigment epithelial cell line and of pig primary retinal pigment epithelial cells. Toxicol In Vitro. 2002;16(2):193-200.

66. Mannerström M, Mäenpää H, Toimela T, Salminen L, Tähti H. The phagocytosis of rod outer segments is inhibited by selected drugs in retinal pigment epithelial cell cultures. Pharmacol Toxicol. 2001;88(1): 27-33.

67. Cho KS, Yoon YH, Choi JA, Lee SJ, Koh JY. Induction of autophagy and cell death by tamoxifen in cultured retinal pigment epithelial and photoreceptor cells. Invest Ophthalmol Vis Sci. 2012;53(9):5344-5353.

68. Eisner A, Toomey MD, Falardeau J, Samples JR, Vetto JT. Differential effects of tamoxifen and anastrozole on optic cup size in breast cancer survivors. Breast Cancer Res Treat. 2007;106(2):161-170.
69. Colley SM, Elston JS. Tamoxifen optic neuropathy. Clin Experiment Ophthalmol. 2004;32(1):105-106.

70. Kadayifcilar S, Boyacioglu S, Kart H, Gursoy M, Aydin P. Ocular complications with high-dose interferon alpha in chronic active hepatitis. Eye (Lond). 1999;13(Pt 2):241-246.

71. Cuthbertson FM, Davies M, McKibbin M. Is screening for interferon retinopathy in hepatitis C justified? Br J Ophthalmol. 2004;88(12): 1518-1520.

72. Panetta JD, Gilani N. Interferon-induced retinopathy and its risk in patients with diabetes and hypertension undergoing treatment for chronic hepatitis $\mathrm{C}$ virus infection. Aliment Pharmacol Ther. 2009;30(6):597-602.

73. Guyer DR, Tiedeman J, Yannuzzi LA, et al. Interferon-associated retinopathy. Arch Ophthalmol. 1993;111(3):350-356.

74. Schapira D, Nahir AM, Hadad N. Interferon-induced Raynaud's syndrome. Semin Arthritis Rheum. 2002;32(3):157-162.

75. Jenisch T, Dietrich-Ntoukas T, Renner AB, Helbig H, Gamulescu MA. [Combined retinal artery and vein occlusions associated with interferon beta therapy]. Ophthalmologe. 2012;109(1):71-75. German.

76. Rubio JE, Charles S. Interferon-associated combined branch retinal artery and central retinal vein obstruction. Retina. 2003;23(4):546-548.

77. Fraunfelder FW, Fraunfelder FT. Interferon alfa-associated anterior ischemic optic neuropathy. Ophthalmology. 2011;118(2):408-411. e1.

78. Kirchhoff A, Kirchhoff U, Lafrenz M, Guthoff R. [Bilateral AION after the combined therapy of hepatitis $\mathrm{C}$ with $\mathrm{PEG}$-interferon alpha2B and ribavirin]. Klin Monbl Augenheilkd. 2004;221(9):791-793. German.

79. Wei YH, Wang IH, Woung LC, Jou JR. Anterior ischemic optic neuropathy associated with pegylated interferon therapy for chronic hepatitis C. Ocul Immunol Inflamm. 2009;17(3):191-194.

80. Oishi A, Miyamoto K, Kashii S, Yoshimura N. Retinopathy is not the only ocular symptom: myasthenia gravis in association with interferon therapy. Br J Ophthalmol. 2005;89(11):1542-1543.

81. Oishi A, Miyamoto K, Kashii S, Yoshimura N. Abducens palsy and Sjogren's syndrome induced by pegylated interferon therapy. $\mathrm{Br} J$ Ophthalmol. 2007;91(6):843-844.

82. Hammam T, McFadzean RM, Ironside JW. Anti-hu paraneoplastic syndrome presenting as bilateral sixth cranial nerve palsies. J Neuroophthalmol. 2005;25(2):101-104
OncoTargets and Therapy

\section{Publish your work in this journal}

OncoTargets and Therapy is an international, peer-reviewed, open access journal focusing on the pathological basis of all cancers, potential targets for therapy and treatment protocols employed to improve the management of cancer patients. The journal also focuses on the impact of management programs and new therapeutic agents and protocols on

\section{Dovepress}

patient perspectives such as quality of life, adherence and satisfaction The manuscript management system is completely online and includes a very quick and fair peer-review system, which is all easy to use. Visit http://www.dovepress.com/testimonials.php to read real quotes from published authors. 